\title{
STRATEGIC GROUPING IN ITO SERVICES AS A MEAN OF IDENTIFYING THE MAIN COMPETITORS FOR HUMAN RESOURCES
}

\author{
R. Radev* \\ The University of National and World Economy, Sofia, Bulgaria
}

\begin{abstract}
This publication aims to present the strategic groups of competitors in the outsourcing sector in Bulgaria. In the core of strategic grouping presented here is the identification of the product-market profile of a sample of 35 main competitors. It is a part of the research of the HR capacity sustainability of Bulgaria as one of the leading destinations for providing outsourcing services. The methodology for the identification of the strategic groups consists of three main steps. The first step purpose is to identify the population of the main competitors. The vital part of this step is the definition of BPO and ITO services, which are of interest to the research. The second step refers to identifying individual companies, supplying one or another BPO/ITO service. For a more detailed assessment, it is also essential to define the depth of BPO/ITO services provided by every competitor. This profiling helps to determine the intensity of competition for each service category. The third step goal is to identify strategic groups of competitors that employ human resources with similar technical and language skills. This grouping helps companies to define appropriate human resources policies to make them more competitive in attracting and retaining the desired human resources.
\end{abstract}

Key words: Product - market profile, BPO, ITO, Human resources, sustainable capacity

\section{INTRODUCTION}

This paper represents part of the study for defining the Human resource capacity of Bulgaria for the companies in the outsourcing sectors. The study aims to identify the opportunities for business growth in Bulgaria. Three groups of people are taken into account as the main factors of human resources sustainability. The first group consists of people employed in outsourcing companies in Bulgaria and the companies from the IT sector. The second group includes a young workforce of the age of 15-39 years. The third group consists of two subgroups - students graduating from their high schools (basic and vocational) and students enrolled in the tertiary education system. The subject of interest of the current paper is the first group - people employed in outsourcing companies in Bulgaria and the companies from the IT sector. In this connection, 35 companies were in the focus of the study, with approximately 30000 people employed.

\footnotetext{
*Correspondence to: Assos. Prof. Dr. Radko Radev, The University of National and World Economy, Sofia, Bulgaria,radko_radev@unwe.eu,0894780098
}

The thesis of the paper is that a strategic grouping concept is a vital instrument for defining direct and indirect competitors for the customers on a global base and the competition for human resources in a specific region or country. The grouping is done based on the product-market profile of the competitors and technical and language skills possessed by their employees. This grouping helps companies to define appropriate human resources policies to make them more competitive in attracting and retaining human resources.

The main goal of the article is to define strategic groups of competitors for human resources in the outsourcing sector in Bulgaria. There are four tasks which help to complete the main goal: 1) Determining the intensity of services supplied by competitors - both of BPO and ITO services; 2) Identifying the individual companies' portfolio and the depth of BPO and ITO services they provide; 3) Grouping the competitors into different strategic groups for ITO and BPO services they supply; 4) Identifying the number of 
people they employ, offices occupied by competitors and the cities where they are.

\section{METHODOLOGY}

The first step consists of the identification of the population of the main competitors to be analyzed. The critical part of this step is the definition of BPO and ITO services, which are of interest to the research. This step finishes with the creation of outsourcing categories services - company matrix in the form of a table.

The second step completed refers to the identification of the individual companies, supplying one or another BPO/ITO service. For a more detailed assessment, it is also essential to define the depth of BPO/ITO services provided by every single competitor. The result of this profiling is identifying and grouping the companies according to employees' language and professional characteristics.

The third step aims to identify the service profile for the outsourcing industry in Bulgaria. It refers to the country as a whole and for specific regions (cities), representing the interest of opportunities for outsourcing companies to develop their business in Bulgaria. The aggregate service profile helps determine the intensity of competition for each service category. The intensity is a result of the number of companies offering one or another outsourcing service. Its identification helps to define the specialization of the existing workforce in ITO services.

All these steps were possible by using only secondary sources of information: corporate web sites, outsourcing associations' reports, specialized magazines, different researches, etc.

\section{LITERATURE REVIEW}

The concept for strategic groups is a crucial instrument for competitive analysis and strategic management. (1) There are two main approaches used to identify competitors industrial and market-oriented (costumeroriented). In the core of identifying competitors through the industrial approach are the characteristics of similar products. The philosophy of the second one places the central role the same needs of the target market (costumers), which could be satisfied by different products/services. (2) Without ignoring anyone of the two approaches, we accept one broader concept which is based on the philosophy of value creation. (3-5) This concept is valid for $\mathrm{B} 2 \mathrm{C}$ as well as for $\mathrm{B} 2 \mathrm{~B}$ formats even though there is a difference between them. (6) The companies supplying outsourcing services fall mainly within B2B form. (7) The competitive analysis in the outsourcing business can be completed on three levels: for every single category of service, for any of both BPO and ITO classes and the sector as a whole. (8) From a geographical point of view, competition analysis, including strategic groups, has to be made for a given country, region, continent, or on a global base. (9-10)

In general, strategic grouping is made on the base of similarity of a business model and a business strategy among competitors. (2) There are some typical characteristics usually used to determine different strategic groups: product variety, geographical coverage, target markets, product characteristics, price levels, etc. (1112). The competition analysis is completed among the competitors within strategic groups (called direct competitors) and between different strategic groups (indirect competitors) is a useful instrument in outsourcing (13).

The value creation approach gives a broader perspective of competitive analysis. Except for the product -market point of view, the valuecreation method includes all essential areas of competences and resources. (14) The perception of human resources as management function (15-18) and the assessment of HR capacity sustainability is a crucial component in decision-making for business growth in the outsourcing companies. (19) In this publication, strategic groups' identification is perceived as a critical, strategically important tool. The outsourcing companies can use it to identify their direct and indirect competitors for human resources with the required language and technical skills - the perception of strategic groups in this way in the next part of the article.

\section{RESULTS \\ 1. The intensity of competition in BPO and ITO services}

In defining HR capacity sustainability, thirtyfive (35) competitors were identified. Five managers of different companies, operating in Bulgaria, approve the list with the companies' names, which fell within the research sample. Based on the preliminary research, different categories and subcategories BPO and ITO services were defined. They are used to determine the service profile of each 
competitor and for the country as a whole. On the other hand, the employees 'profile in the industry can be defined for every single competitor and for the outsourcing sector totally.

The analysis examined ten BPO and seven ITO services as follows Table 1:

Table 1. List of categories BPO and ITO services

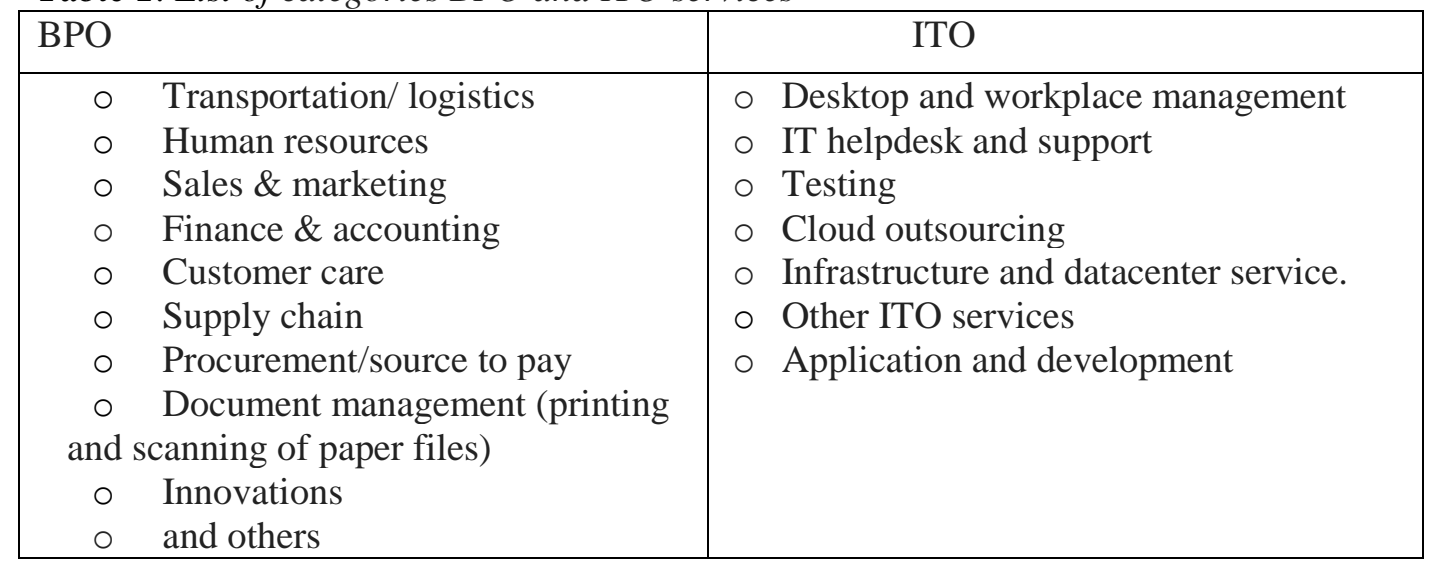

In the first and the second IT categories (Desktop and workplace management and IT helpdesk and support), additional services subcategories are identified. There are two subcategories within the Desktop and Workplace category: Line Technical Support Analysis and Line Support Analysis (non-IT). The IT help desk category from its side consists of the following eight subcategories: IT operations, NET Web \& Middleware, Backup \& Storage, Batch \& Scheduling, Database, Network, UNIX, and Windows. This disaggregation gives a more accurate view of the study.
The intensity of competition in BPO services The review of each of the categories testifies to the fact that they are offered with varying intensity. The highest intensity of BPO services is identified in Customer care and Document management. They are provided by thirty (30) companies or $86 \%$ of all surveyed. The second most offered BPO service is Finance and accounting - offered by twentyseven (27) companies or $77 \%$. The last place is taken by Transportation and logistics, which is provided by nine companies or $9 \%$ of the total. (Figure 1)

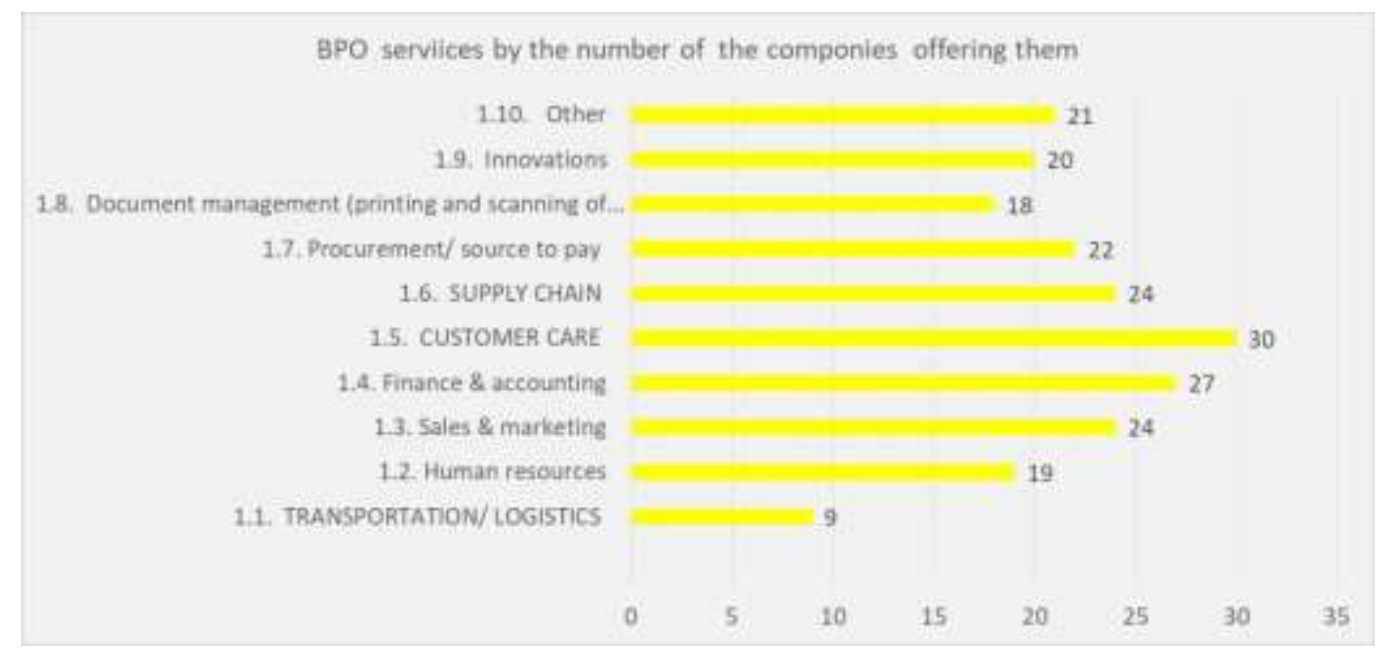

Figure 1

The intensity of competition in ITO services: it can be seen(from the figure below) that the intensity of competition differs for the different categories of ITO services. There are three main ITO categories with the 25 companies supplying them -Desktop and workplace management, IT helpdesk and support and Infrastructure, and datacenter services. Testing is offered by 21 of the companies or $71 \%$ of the whole aggregate. (Figure 2) 


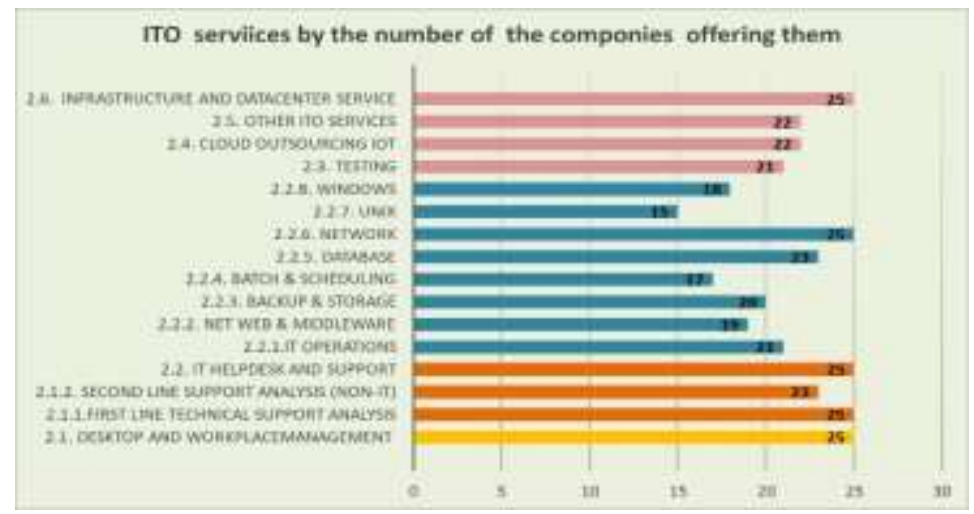

Figure 2

2. Companies' portfolio and depth of BPO and ITO services they supply

BPO services depth: The average depth identified is seven offered in the categories of BPO services. The depth between 7 and 10 BPO categories is observed in 19 of the companies or $15 \%$ of all aggregate.
Nine companies are supplying between 5-6 services, which equals to $26 \%$ relative share. The share of the companies which offer at least one and a maximum of four BPO services is $14 \%$ or nine. The number of companies without any BPO services from the list is 3 or $6 \%$. (Figure 3)

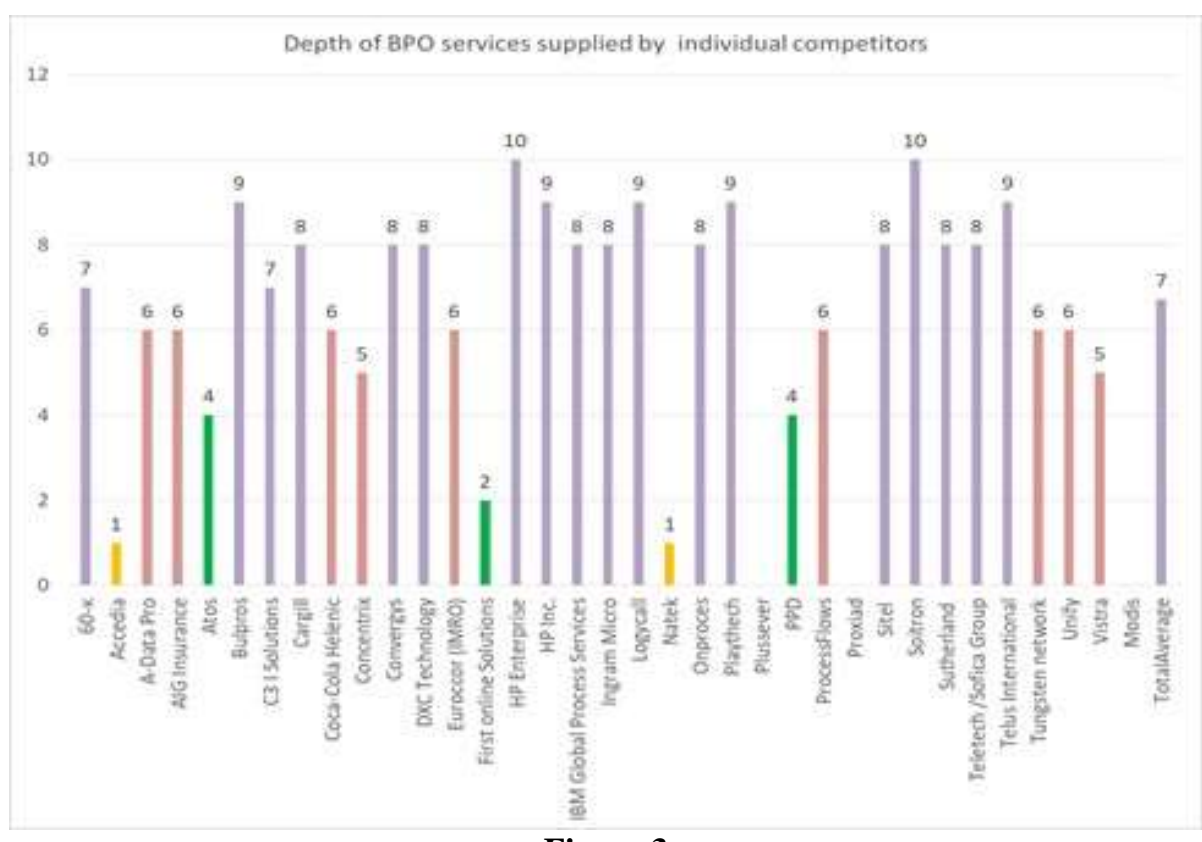

Figure 3

ITO services depth: The average depth of ITO services supplied by the companies from the surveyed is nine categories offered. The maximum depth is 14 , and it is available in 13 companies. In one of the companies, the depth is 13. There are seven companies with ITO service depth between 7 and 11 .

In 5 of the companies, the depth portfolio is from 4 to 6 . The fourth group includes five companies with a depth of less than 4 ITO services supplied. There are three companies without any ITO operations included in their service portfolio. (Figure 4)

\section{Strategic groups of competitors in ITO services}

The analysis of the depth of ITO services supplied helps to identify five strategic groups of competitors in terms of human resources and business operations. The result of this profiling is identifying and grouping the companies, potential "targets" from which employees with appropriate characteristics can be attracted.

The first strategic group of competitors consists of $\mathbf{1 4}$ companies (Atos, Bulpros, Concentrix, HP Enterprise, HP Inc., IBM GPS, Natek, Sitel, Soitron, Sutherland, Telus International, Unify and Process Flows) 
or $40 \%$ of all companies included in the current survey. Their ITO services portfolio depth is between 12 and 14 . The companies from this group are ITO services direct competitors for human resources and selectively for business operations.

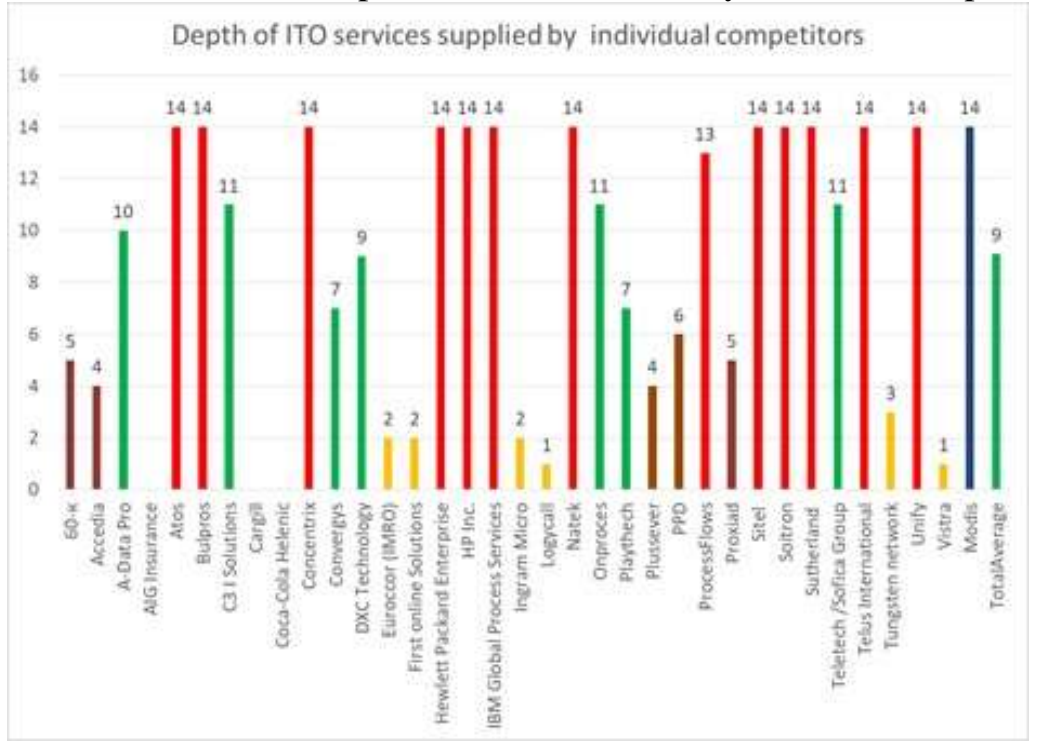

Figure 4

- The second strategic group includes seven companies (Teletech, C3 I Solutions, on process A-data pro and DXC Technology, Convergys, and Playtech) with ITO service depth between seven and eleven or $23 \%$ of the total. The ITO service depth of these companies represents about 50 to $79 \%$ of companies' depth from the first strategic group. The companies from this group are ITO services direct competitors for human resources and selectively for business operations.

The third strategic group comprises five companies $(60-\mathrm{K}$, Accedia, Pulsever, Proxiad, and PPD) with ITO services depth from 4 to 6 , which is about 29 to $42 \%$ of the companies' depth the first strategic group. The companies from this group have to be considered partly main competitors for human resources and business.

The fourth group includes five companies (Eurccor, First online solutions,

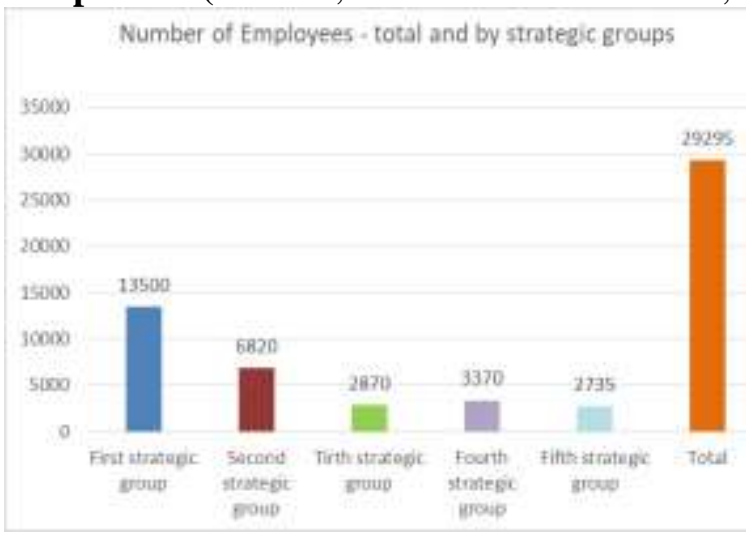

Inagram Micro, Logycall, and Tungsten international) with a depth of less than four ITO services supplied. These companies can be considered as indirect competitors for human resources.

The last group is formed by four companies (AIG Insurance, Coca-cola Cargill, and Vistra), which don't include ITO services in their portfolio. They are also ITO companies' indirect competitors for human resources.

\section{Number and structure of people employed by strategic groups}

As already explained, the total number of employees in 35 companies is $29 ' 295$. The individual strategic groups have a different relative weight of this number. Except for the number of employees, there are differences in the technical and language skills of people employed in companies from different strategic groups. (Figure 5)

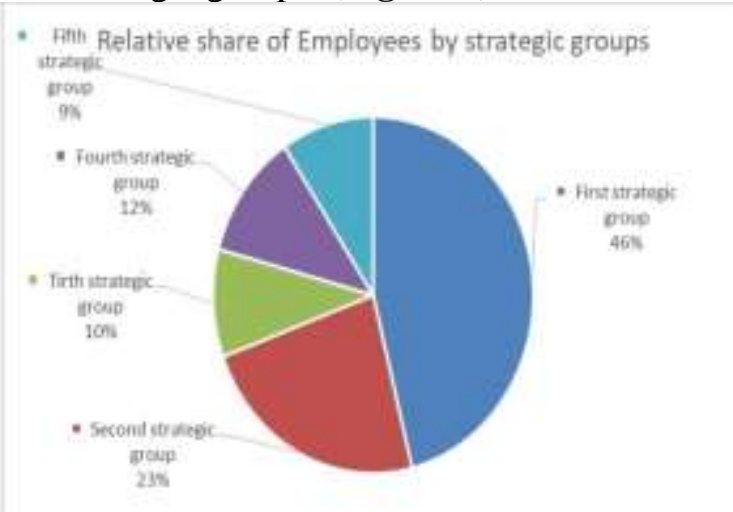

Figure 5 
- The most significant number of employees $(\mathbf{1 3 , 5 0 0 )}$ is observed in the first strategic group. Its relative weight is $\mathbf{4 6 \%}$ of all employees in the selected set of companies. These employees are with technology and language skills matching these needed by ITO companies.

- The second strategic group is also the second most important according to the number of employees - $\mathbf{6 , 8 2 0}$, or $23 \%$ of all employed. The employees from this group are also with technical and language skills matching these needed by

- ITO companies.

- According to the number of employees, third place is taken by the fourth strategic group - 3370, with a relative share of 12\%. These employees possess partly technical skills that match MODIS's needs but have appropriate language knowledge.

- In fourth and fifth places, with a similar number of employees, are the third
$R A D E V R$. group (2870 people) and fifth strategic group (2735). Their shares of total employment in the 35 surveyed companies are respectively 10 and $9 \%$. They possess mainly appropriate language skills.

\section{Companies, according to the number of offices they occupy and city coverage}

The surveys results show that there are different cases according to the number of offices held by individual competitors occupy. This information indicates that some of the companies expand their business operations in Bulgaria. Most of the companies (21) have only one office placed in Sofia. Companies that occupy two offices are 9 or $26 \%$. There is one case with a company with three offices and three cases with companies holding four offices. There is only one case in which a company has five offices and more in 5 different cities. (Table 2)

Table 2. Companies according to the number of offices they occupy

\begin{tabular}{|l|r|r|l|}
\hline Number of offices & $\begin{array}{l}\text { Number of } \\
\text { companies }\end{array}$ & $\begin{array}{l}\text { Percent of } \\
\text { the } \\
\text { companies }\end{array}$ & Names of the companies \\
\hline One office & 21 & $60 \%$ & All except companies from the next rows \\
\hline Two offices & 9 & & $\begin{array}{l}\text { 1) 60-K, 2) C3 I Solutions, 3) Cocentrix, 4) } \\
\text { Euroccor, 5) Proxiad, 6) Sitel, 7) Teletech, 8) } \\
\text { Telus International, 9) Unify }\end{array}$ \\
\hline Three offices & 1 & $3 \%$ & 1) A - Data pro \\
\hline Four offices & 3 & $9 \%$ & 1)A Data pro, 2) Bulpros, 3) Sutherland \\
\hline Five and offices and $\mathrm{m}$ & 1 & $3 \%$ & 1) First online solution \\
\hline Total & 35 & $100 \%$ & \\
\hline
\end{tabular}

Cities coverage: The results of the survey show a geographical expansion of some of the companies. There are six cities where outsourcing companies operate. Every one of all 35 companies occupies offices in Sofia. There are seven companies' with offices in
Plovdiv; six companies are with offices in Varna; two companies have offices in Burgas and Veliko Tarnovo. There is only one company with an office in Blagoevgrad. (Table 3)

Table 3. Companies according to the cities where they operate

\begin{tabular}{|l|r|r|l|}
\hline City & $\begin{array}{l}\text { Number of } \\
\text { companies }\end{array}$ & $\begin{array}{l}\text { Percent of } \\
\text { the } \\
\text { companies }\end{array}$ & Names of the companies \\
\hline Sofia & 35 & $100 \%$ & All \\
\hline Plovdiv & 7 & $20 \%$ & $\begin{array}{l}\text { 1) 60-K, 2) A-Data pro, 3) Bulpros, 4) } \\
\text { Proxiad, 5) Teletech, 6) Telus, 7) Unify }\end{array}$ \\
\hline & & & $\begin{array}{l}\text { 1)C3 Solution, 2) Cargill, 3) Concentrix, 4) } \\
\text { First online solutions, 5) Sitel and 6) } \\
\text { Vurna }\end{array}$ \\
\hline Burgas & 6 & $17 \%$ & Sutherland \\
\hline Veliko Tarnova & 2 & $6 \%$ & First online solutions and 2) Sutherland \\
\hline Blagoevgrad & 2 & $6 \%$ & First online solutions, 2) A-Data pro \\
\hline Total & 1 & $3 \%$ & First online solutions \\
\hline
\end{tabular}




\section{CONCLUSIONS}

Identifying the BPO/ITO services portfolio of chosen competitors has to be accepted as a significant part of defining sophisticated HR sustainable capacity for the specific regions (cities).

The concept of strategic groups is an essential tool in strategic management. Traditionally, it is used to identify competitors who follow a similar competitive approach and productmarket scope. Through it, the companies in the outsourcing services sector determine their strategic market positioning in terms of service sectors in the economy, services offered, pricing policy, and value-added in general. In this publication, the grouping of competitors into strategic groups is performed to identify direct competitors in terms of human resources, which have a similar language and professional profile desired by a company. Strategic grouping can be performed for the outsourcing sector as a whole, for the individual classes of BPO and ITO services and the different categories falling within their boundaries. The results from current research are a good base for further detailed profiling of the competitors, including management, business strategies, marketing strategies, financial results, etc. If additional information is needed, other research can be executed by using primary sources.

\section{REFERENCES}

1. Porter. E. M., Competitive Strategy: Techniques for Analyzing Industries and Competitors. Simon and Schuster, 2008, p.173-201.

2. Aaker, D. A., McLoughlin, D., Strategic Market Management: Global Perspectives. John Wiley \& Sons, 2009, p.43-45; p.45-46.

3. Kim, W. C., Mauborgne, R. A., Blue Ocean Strategy: How to Create Uncontested Market Space and Make the Competition Irrelevant. Harvard Business Review Press, 2015.

4. Mahajan, G., Value Creation: The Definitive Guide for Business Leaders. SAGE Publishing India, 2016.
$R A D E V R$.

5. Cook, H. E., Wissmann, L. A., ValueDriven Product Planning and Systems Engineering. Springer Science \& Business Media, 2007.

6. Meyer, S., Major Differences Along the Supply Chain Between B2B and B2C Marketing with Regard to "Fast-MovingConsumer-Goods" (FMCG). GRIN Verlag, 2007.

7. Bussler, Ch., B2B Integration: Concepts and Architecture. Science \& Business Media, 2013.

8. Drache, D., Gertler, M.S., New Era of Global Competition: State Policy and Market Power. McGill-Queen's Press MQUP, 1991, p. 55-80.

9. Vagadia. B., Strategic Outsourcing: The Alchemy to Business Transformation in a Globally Converged World. Springer Science \& Business Media. 2011.

10. Blokdyk, G., Competitive Analysis A Complete Guide - 2020 Edition. Emereo Pty Limited, 2020.

11. Enz., C. A., Hospitality Strategic Management: Concepts and Cases. John Wiley and Sons. 2008, p. 199-201.

12. Johnson, G., Scholes, K., Whittington, R., Exploring Corporate Strategy, 8-th Edition. Pearson. Education, 2019, p. 7377.

13. Bengtsson, M., Climates of Global Competition. Routledge, 2003, p. 24-29.

14. Fahy, J., The Role of Resources in Global Competition. Routledge, 2002.

15. Schermerhorn, J. R., Jr., Introduction to Management. John Wiley \& Sons, 2011.

16. Price, A., HumanResource Management in a Business Context, 2-th Ed. Thompson, 2004.

17. Armstrong, M., A Handbook of Human Resource Management Practice, 10-th edition. Kogan Page, London, 2010.

18. Ulrich, D., Brockbank, W., Younger, J., Nyman, M., Allen, J., HR Transformation: Building Human Resources From the Outside In. McGraw Hill Professional, 2010.

19. Taplin. R., Outsourcing and Human Resource Management: An International Survey, Routledge, 2007. 